\title{
Balancing clinical risk with countertransference management protects alliance
}

\author{
João F. Barreto, ${ }^{1-3}$ Paula Mena Matos ${ }^{1,2}$ \\ ${ }^{1}$ Center for Psychology at University of Porto; ${ }^{2}$ Faculty of Psychology and Education Science, University of Porto; ${ }^{3}$ Polytechnic Institute \\ of Porto, Portugal
}

\begin{abstract}
The working alliance has been recognized as a predictor of psychotherapy outcome across therapeutic orientations. Despite mixed findings regarding the effect of problem severity on the alliance formation, there is evidence suggesting that therapist factors may interfere in this association. This study examined how clients' baseline clinical features affected the early alliance and the possible role of therapists' countertransference management as a mediator. Thirteen therapeutic dyads were assessed at 2 different time points. Clients' clinical dimensions were assessed prior to the 2nd session, and therapists' countertransference management and clients' ratings of the alliance were measured after the 2nd session. Positive associations were found between clients' subjective wellbeing, social functioning, risk, and global psychological distress and countertransference management dimensions and total score. Empathy-based countertransference management suppressed the negative impact of clinical risk on alliance. Our findings suggest that clinical problems activate countertransference management, which in turn may buffer their negative effect on alliance.
\end{abstract}

Key words: Countertransference management; Therapeutic alliance; Working alliance; Suppressor effect.

Correspondence: Paula Mena Matos, Faculdade de Psicologia e de Ciências da Educação, Universidade do Porto, Rua Alfredo Allen, 4200-135, Porto, Portugal.

Tel: (00351) 22607970.

E-mail: pmmatos@fpce.up.pt

Citation: Barreto, J.F., \& Mena Matos, P. (2017). Balancing clinical risk with countertransference management protects alliance. Research in Psychotherapy: Psychopathology, Process and Outcome, 20(3), 179-186. doi: 10.4081/ripppo.2017.279

Acknowledgments: the authors wish to thank Frederick G. Lopez for the kind and thoughtful exchange of ideas regarding this paper.

Contributions: both authors have made substantial contributions to the conception of this work and the collection and treatment of the data presented, as well as the drafting and revision of the manuscript. Both approved its final version and agree to be accountable for any questions related to the accuracy or integrity of any part of the work.

Conflict of interest: the authors declare no conflict of interest.

Funding: this work has been supported by the Foundation for Science and Technology (FCT) Grant SFRH/BD/96922/2013 and partially by Polytechnic Institute of Porto fundings (Programa de Formação Avançada de Docentes, Editions 2012 and 2013) earned by João F. Barreto.

Received for publication: 17 May 2017.

Revision received: 14 July 2017.

Accepted for publication: 22 August 2017.

This work is licensed under a Creative Commons Attribution NonCommercial 4.0 License (CC BY-NC 4.0).

C) Copyright J.F. Barreto and P.M. Matos, 2017

Licensee PAGEPress, Italy

Research in Psychotherapy:

Psychopathology, Process and Outcome 2017; 20:179-186

doi:10.4081/ripppo.2017.279

\section{Introduction}

The working alliance has been widely recognized as an important predictor of psychotherapy outcome across therapeutic orientations (Horvath, Del Re, Flückiger, \& Symonds, 2011). In particular, evidence suggests that client rated alliance and assessment at early stages of the therapeutic process may be especially relevant for outcome prediction (Constantino, Castonguay, \& Schut, 2002; Horvath $\&$ Bedi, 2002; Zilcha-Mano et al., 2015). Therefore, research has focused on identifying pre-treatment determinants of alliance, both in clients and in therapists.

Most studies in the field suggest that clients' interpersonal functioning and positive expectations of psychotherapy are important predictors of the therapeutic alliance, but the findings on the relation between pre-treatment symptoms and the alliance are inconsistent (Gibbons et al., 2003; Horvath, 1994). Admittedly, as put by Gibbons et al. (2003), highly symptomatic clients may be more hopeless and less able to engage with the therapist or, contrarily, have greater motivation to engage and alleviate their distress. More consensus surrounds the notion that personality disordered clients are more prone to ruptures in the therapeutic alliance, given their emotional lability or constriction and their restricted range of interpersonal behavior (Tufekcioglu, Muran, Safran, \& Winston, 2013).

Although there is evidence that therapists' effects on the alliance-outcome correlation may be more important than clients' effects (Del Re, Flückiger, Horvath, Symonds, \& Wampold, 2012), there is less research on what specific therapist factors contribute to better alliances. The most consistent therapist predictors seem to 
concern relational skills (Nissen-Lie, Monsen, \& Rønnestad, 2010). In two comprehensive reviews of therapists' personal attributes and in-session activities that influence the therapeutic alliance, Ackerman and Hilsenroth (2001, 2003) identified attributes such as being rigid, uncertain, critical, distant, tense, and distracted, and techniques such as over-structuring therapy, inappropriate self-disclosure, unyielding use of transference interpretation, and inappropriate use of silence as negative factors. Positive factors included being flexible, honest, respectful, trustworthy, confident, warm, interested, and open, as well as techniques such as exploration, reflection, noting past therapy success, accurate interpretation, facilitating the expression of affect, and attending to the client's experience. Taken together, these results draw attention on the way therapist factors convert into in-session therapist activities that finally affect the clients' perspective on the alliance. At the same time, the extent to which therapists' personal reactions seem to be involved suggests that countertransference (CT) and its management (Gelso \& Hayes, 2007) may play an important role in the dynamics of alliance formation.

Some findings concerning therapists' attachment organization appear to corroborate this claim. For instance, there is evidence that therapists' attachment insecurity may negatively affect the alliance and therapist empathy (e.g., Sauer, Lopez, \& Gormley, 2003; Rubino, Barker, Roth, \& Fearon, 2000), apparently indicating that therapists' unresolved personal issues are at stake. Additionally, some studies suggest that the severity of clients' problems interact with therapists' attachment dimensions in affecting the alliance, such that the relation of therapists' attachment with alliance only becomes relevant with the most severely impaired patients (Bucci, Seymour-Hide, Harris, \& Berry, 2015; Schauenburg et al., 2010). Schauenburg et al. (2010) wanted to predict alliance from therapists' dimensional ratings of the Adult Attachment Interview (AAI) in terms of security-insecurity and dismissivenesspreoccupation. They studied 31 psychodynamically oriented psychotherapists who treated 1381 clients and analyzed the data with multilevel regression analyses. In line with previous findings (e.g., Ligiéro \& Gelso, 2002), there were no main effects of therapists' attachment on alliance ratings. However, security-insecurity worked as a moderator of client variables, i.e., attachment security of therapists was associated with good alliances only for clients with high levels of interpersonal problems and symptomatic impairment before therapy. More recently, Bucci et al. (2015) conducted a study with 30 therapistclient dyads in which, again, no correlations were found between therapists' attachment ratings as either secure, dismissing, preoccupied, or fearful and the alliance. Nonetheless, splitting the sample in high- and low-symptomatic groups, significant correlations were found between therapists' dismissing, preoccupied, and fearful dimensions and alliance ratings. Apparently, thus, clients' symptoms and therapists' attachment dimensions studied separately relate inconsistently to alliance; but an interaction effect may be revealed when considered in conjunction. Once more, therapists' CT responses under the pressure of clients' clinical characteristics seem to be involved in the development of alliance.

CT management has been defined by Gelso and Hayes (2007) as a process by which therapists try to prevent detrimental effects of CT, repair or minimize these effects, and use CT to benefit the work with clients. It has been considered a promising element of effective therapeutic relationships by the American Psychological Association's second Task Force on Evidence-Based Therapy Relationships (Norcross \& Wampold, 2011). Five factors are expected to underlie successful CT management: therapist self-insight, self-integration, empathy, anxiety management, and conceptualizing skills (Gelso \& Hayes, 2007) (although the authors assume a definition of CT consisting of therapist reactions in which personal unresolved conflicts are implicated, we believe it is arguable that these factors are involved in the successful management of therapists' reactions as a whole, especially considering that unresolved issues are always present to some degree). Although research suggests that CT management is positively related to outcome (Hayes, Gelso, \& Hummel, 2011), studies on its specific impact on alliance are very scarce. To our knowledge, the only published results available come from a quantitative case-study conducted by Rosenberger and Hayes (2002) in which they examined consequences of the client's verbalizations involving therapist's areas of unresolved conflict on therapist's avoidant behavior and social influence, working alliance, and session impact, and the extent to which self-reported CT management might mitigate these effects. Pertaining to our variable of interest, $\mathrm{CT}$ management was found to correlate positively with the client's ratings of alliance, therapist's perceptions of her social influence attributes, and session depth, both rated by client and therapist.

In this study, we want to examine the effect of clients' clinical features on the initial alliance, and the possible interference of therapists' factors in the process. In particular, we will assess how clients' baseline clinical dimensions impact client-rated early alliance and the possible role of therapists' CT management as a mediator. We expect that more distressed and symptomatic clients will put therapists' relational abilities to the test. We thus hypothesize that: i) clients' distress and symptom severity will have a negative impact on alliance; and ii) this impact will be at least partially mediated by a negative effect on CT management. Alternatively, as mentioned earlier, distress may show positive associations with alliance (Gibbons et al., 2003), in which case we don't expect CT management to mediate this effect at early sessions. We will examine the relationships among different components of distress, alliance, and CT management (partial and total scores), given the lack of previous findings on 
which more specific hypotheses might be supported, and admitting that different patterns of associations may be expected due to the complexity of mutual reactivity within the dyad. This paper intends to present and discuss preliminary results from a wider ongoing longitudinal study.

\section{Methods}

\section{Participants}

Thirteen independent therapeutic dyads in adult psychotherapy working in different community contexts (private practice, college counseling centers, and community mental health centers) voluntarily participated in this study. Clients included nine women and four men whose ages ranged from 19 to 54 years $(\mathrm{M}=25.5, \mathrm{SD}=10.6)$. Therapists ranged from 28 to 55 years of age $(M=40.2$, $\mathrm{SD}=7.8$ ), including 10 women and three men who acknowledged between four and twenty three years of experience $(\mathrm{M}=13.5, \mathrm{SD}=6.3)$. The reported predominant theoretical orientation was psychoanalytic/dynamic in four cases, humanistic/experiential in two, cognitive-behavioral in three, systemic in one, eclectic/integrative in two, and assimilated cognitive-behavioral and eclectic/integrative in one. All participants were Caucasian.

\section{Instruments}

Clinical Outcomes in Routine Evaluation - Outcome Measure (CORE-OM; Evans et al., 2000; Portuguese version by Sales, Moleiro, Evans, \& Alves, 2012) is a 34item self-report questionnaire designed to measure different aspects of adults' mental health in the context of psychological therapies. It is not a diagnostic tool and can be used in a variety of contexts and intervention modalities for pre-treatment assessment and/or as a measure of change during or after therapy. Clients are asked to report on subjective well-being ( 4 items, $\alpha=.76 ;$ e.g., I have felt optimistic about my future), problems/symptoms (12 items, $\alpha=.90 ;$ e.g., I have felt totally lacking in energy and enthusiasm), social functioning (12 items, $\alpha=.88$; e.g., I have felt humiliated or shamed by other people), and risk (to self and to others; 6 items; $\alpha=.65$ after dropping items 9 and $34 ;$ e.g., I have threatened or intimidated another person) on a 5-point Likert-type scale referring to the previous week. In this study, we used the total score (psychological distress; $\alpha=.94$ ) and each of the subscales. Items 9 and 34 both referred to self-harm (I have thought of hurting myself, I have hurt myself physically or taken dangerous risks with my health). They were dropped in the risk dimension measurement following strictly statistical criteria (higher impact on reliability improvement) and considering that two items for each type of risk (concerning self and others) remained available.

Working Alliance Inventory - Short Revised (WAI-SR; Hatcher \& Gillaspy, 2006; Portuguese version by Ramos, 2008 ) is a 12 -item self-report scale comprising three di- mensions - bond (e.g., I feel that my therapist appreciates me), tasks (e.g., I believe the way we are working with my problem is correct), and goals (e.g., My therapist and I are working towards mutually agreed upon goals) - with four items each and rated on a 5-point Likert-type scale. Following results from the Portuguese adaptation and in line with previous findings in alliance research (e.g., Hatcher \& Barends, 1996), tasks and goals were merged in a single dimension $(\alpha=.92)$; and item 5 (My therapist and I respect each other, which loaded on the tasks/goals factor in the Portuguese version) was dropped from the bond score $(\alpha=$ .90). The total scale's Cronbach's alpha was .93.

Countertransference Factors Inventory - Direct (CFI; Gelso, Fassinger, Gomez, \& Latts, 1995; Portuguese version by Barreto, Carvalho, \& Matos, 2014). Twenty one-item scale assessing five dimensions underlying effective management of CT: self-insight (5 items; $\alpha=.75$ after dropping item 17 ; e.g., I was aware of feelings in me elicited by the client), empathy ( 6 items, $\alpha=$ .82 ; e.g., I was emotionally 'in tune' with the client), conceptualizing skills ( 4 items; after dropping items 11 and $21, \alpha=.73$; e.g., I was able to conceptualize client's $d y$ namics and issues clearly), self-integration (4 items; e.g., I effectively distinguished between the client's needs and my own needs), and anxiety management (2 items; e.g., I did not become overly anxious in the presence of the client's problems). Self-integration and anxiety management were excluded from analysis due to inadequate internal consistency. CFI uses a 5-point Likert scale and is usually rated by a supervisor or a colleague familiar with the therapist's work. Because we were interested in therapists' CT management in particular sessions (state instead of trait aspects), we used a self-rated sessionspecific form, in line with one previous study (Rosenberger \& Hayes, 2002). This involved a change in the initial instruction (from The therapist: to In this session:) and in the items' wordings (e.g., I was aware of feelings in me elicited by the client instead of Is often aware of feelings in him/her elicited by clients). A total score was calculated excluding item 16 (I used my past experiences to aid in understanding the client, self-integration subscale) in order to improve internal consistency $(\alpha=.76)$. The criterion for excluding this item, as well as items 11 (I identified the dynamics of the therapeutic relationship), 17 (I may have been an impediment to client progress) and 21 (I conceptualize my role in what transpired in the therapeutic relationship) from their respective subscales, has been the magnitude of the impact on internal consistency and took into account the need to retain sufficient items to represent the psychological processes being assessed.

Table 1 contains detailed descriptive data for the measures used in this study. Overall, our sample's CORE-OM scores lie between non-clinical and clinical typical values according to available data from previous studies (Evans et al., 2002), suggesting moderate clinical severity. 


\section{Procedure}

As part of an ongoing longitudinal study on attachment, countertransference, and mentalization, approved by the authors' institutional Ethics Committee, therapists of different orientations were invited by the first author to participate following formal contacts with Portuguese psychotherapy societies and professional organizations and peer nomination technique. Inclusion criteria for therapists included basic training in Psychology or Psychiatry, or a professional certificate from an existing psychotherapy society; and currently working in a setting of outpatient individual psychotherapy. Clients received the invitation and the study's materials through their therapists after the first contact between the two. Therapists were instructed to choose among adult clients voluntarily seeking individual psychotherapy or psychological support. All data were collected anonymously and on-line (LimeSurvey $1.87^{\circledR}$ ), after informed consent, and separately for each individual participant. Regarding the variables reported in this study, CORE-OM (reported by the clients) and socio-demographic data (reported by clients and therapists) were assessed prior to the second session. Client-rated working alliance (WAI-SR) and therapist-rated CT management (CFI) were measured after the second session.

\section{Data analysis}

Given the small sample size, only manifest variables were used, examining data with linear regressions and path analyses. Indirect effects significance was examined with Bootstrap resampling (MacKinnon, Lockwood, \& Williams, 2004). We drew 2000 times a sample (with replacement) from our sample and calculated the bias-corrected bootstrapped confidence intervals. A given indirect effect is significant if the respective confidence interval does not contain zero. All analyses were run with $I B M$ SPSS Statistics 22 and IBM SPSS Amos 23.

\section{Results}

For initial data exploration, we inspected the withindyad correlations among our variables (CORE-OM scores, CT management, and alliance), as presented in Table 2. Given the small sample size, we used Spearman's

Table 1. Descriptive statistics $(\mathrm{N}=13)$.

\begin{tabular}{llccc}
\hline & Mean & SD & Scale \\
\hline CORE-OM & Subjective well-being & 2.02 & 0.90 & $0-4$ \\
& Problems/symptoms & 2.16 & 0.85 & \\
& Social functioning & 1.47 & 0.64 & \\
& Risk & 0.17 & 0.33 & $1-5$ \\
& Total & 1.56 & 0.62 & 1.04 \\
\hline \multirow{2}{*}{ WAI-SR } & Bond & 3.38 & 0.82 & $1-5$ \\
& Tasks/goals & 3.70 & 0.78 & \\
& Total & 3.69 & 0.57 & 0.51 \\
& Self-insight & 3.83 & 0.66 & \\
& Empathy & 3.94 & 0.33 & \\
& Conceptualizing skills & 3.69 & 3.72 &
\end{tabular}

CORE-OM, clinical outcomes in routine evaluation - outcome measure; WAI-SR, working alliance inventory - short revised; CFI, countertransference factors inventory - direct; SD, standard deviation.

Table 2. Within-dyad two-tailed Spearman's rank correlations between clinical features, countertransference management, and alliance $(\mathrm{N}=13)$.

\begin{tabular}{|c|c|c|c|c|c|c|c|c|}
\hline & & \multicolumn{4}{|c|}{ CFI } & \multicolumn{3}{|c|}{ WAI-SR } \\
\hline & & Insight & Empathy & Concept & Total & Bond & Tasks/Goals & Total \\
\hline \multirow[t]{5}{*}{ CORE-OM } & Subjective well-being & .24 & $.57 *$ & $.55+$ & .43 & .10 & .29 & .28 \\
\hline & Problems/symptoms & .34 & .37 & .46 & .38 & .22 & .22 & .30 \\
\hline & Social functioning & .10 & .27 & $.71 * *$ & .29 & -.18 & -.23 & -.23 \\
\hline & Risk & .27 & $.53+$ & .32 & .47 & -.24 & .17 & .08 \\
\hline & Total & .35 & .47 & $.67 *$ & $.48+$ & .06 & .10 & .13 \\
\hline \multirow[t]{3}{*}{ WAI-SR } & Bond & .28 & .16 & -.07 & .08 & & & \\
\hline & Tasks/goals & -.06 & .34 & -.20 & -.02 & & & \\
\hline & Total & .11 & .35 & -.18 & .05 & & & \\
\hline
\end{tabular}

CFI, countertransference factors inventory - direct; WAI-SR, working alliance inventory - short revised; Insight, self-insight subscale of the CFI; Concept, conceptualizing skills subscale of the CFI; CORE-OM, clinical outcomes in routine evaluation - outcome measure. $+\mathrm{P}<.10 ; * \mathrm{P}<.05 ; * * \mathrm{P}<.01$. 
rank correlations and, although we set alpha level at $\mathrm{P}<.05$, we also regarded correlations with $\mathrm{P}<.10$ as indicative of statistical trends.

We further explored the data guided by our main hypotheses and the correlations. Neither clinical variables (CORE-OM scores) nor CT management (CFI total and partial scores) had a significant or nearly significant $(\mathrm{P}<.10)$ effect on alliance or any of its dimensions. However, we found a suppressor effect (MacKinnon, Krull, \& Lockwood, 2000) using different combinations of COREOM risk dimension as an independent variable, WAI-SR total score or WAI-SR dimensions as dependent variables, and CFI total score or CFI empathy as mediating variables. More specifically, we found significant or nearly significant negative direct effects simultaneous with significant or nearly significant positive indirect effects using combinations of these variables. In all cases, the effect was nonsignificant in the absence of the third variable.

With CFI as a mediator, the model explained $37 \%$ of WAI-SR bond variance with significant direct and indirect effects. Replacing CFI for CFI empathy, a significant indirect effect and a nearly significant direct effect on the WAI-SR total score were found, with $29 \%$ of explained variance. Finally, CFI empathy as mediating the relationship of risk to each of the two WAI-SR subscales produced nearly significant indirect effects on both and a significant direct effect in the case of WAI-SR bond, with explained variances of 33\% (WAI-SR bond) and 21\% (WAI-SR tasks/goals). Figure 1 represents each of these models graphically and presents the standardized direct and indirect effects and respective significance values.

Other CORE-OM subscales used as independent variables in combination with the WAI-SR scores as dependent variables and the CFI scales as mediators did not yield either significant or nearly significant results. Finally, given the great variability in therapists' years of clinical experience, we ruled out a possible influence of this variable on the associations mentioned above by examining correlations with our variables of interest and testing experience as an alternative mediator. No significant or nearly significant results were found.

\section{Discussion}

Despite the early stage of our study, the preliminary re-

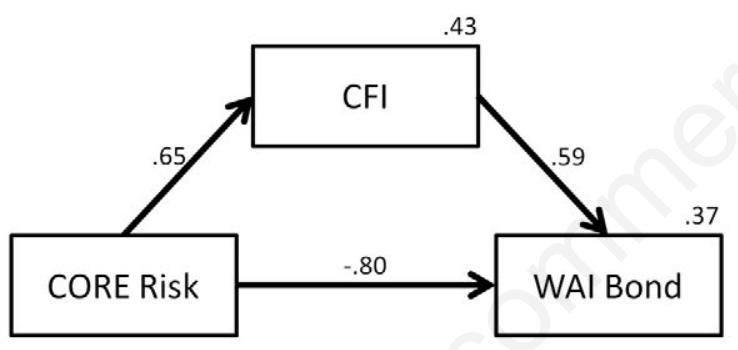

Standardized indirect effect $=.39(p=.050)$

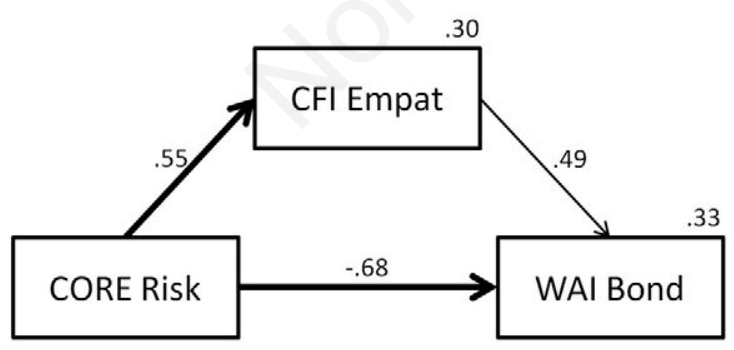

Standardized indirect effect $=.27(p=.085)$

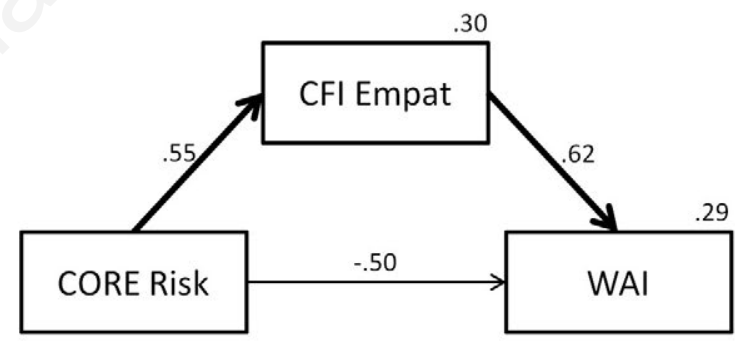

Standardized indirect effect $=.34(p=.046)$

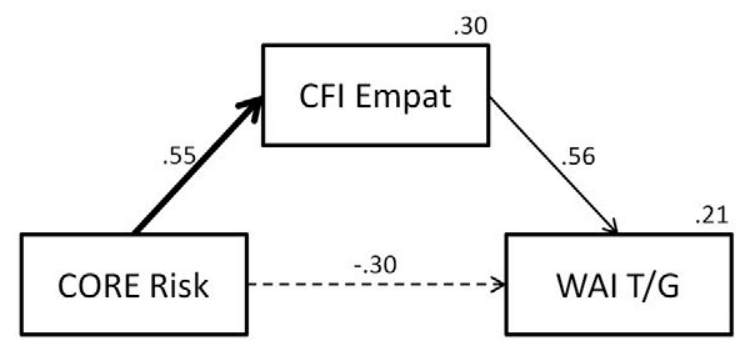

Standardized indirect effect $=.31(p=.069)$

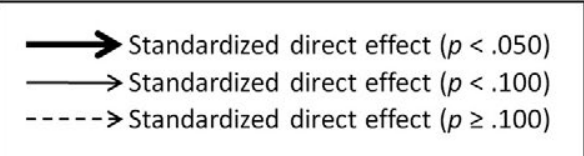

Figure 1. Standardized regression coefficients for the effect of clinical risk on alliance suppressed by countertransference management. CFI=countertransference factors inventory - direct; CFI Empat=empathy subscale of the CFI; CORE Risk=risk subscale of the clinical outcomes in routine evaluation - outcome measure; WAI-SR=working alliance inventory - short revised; WAI Bond=bond subscale of the WAI; WAI T/G=tasks/goals subscale of the WAI. 
sults may signal important patterns in the interrelationships among clients' severity of clinical problems, therapists' CT management, and the early working alliance. Our hypotheses were supported with regard to the importance of CT management on the relationship between pre-treatment clinical problems and alliance, but not always in the anticipated directions. Concerning CT management, positive associations of clients' clinical dimensions with conceptualizing skills may indicate a reactive mobilization of therapists' analytic efforts in the face of clients' difficulties. Similarly, clients' risk of harming themselves and/or others appears to activate CT management, but in this case the empathic component seems to play the leading role, suggesting higher emotional engagement. Taken together, the associations found between clinical dimensions and CT management suggest that clients' difficulties may activate therapists' CT, and the mixed results of previous research concerning their impact on alliance may have to do with the varying success of therapists in managing those reactions. Also, the interest in using session-specific forms of CFI in future studies of CT management is supported.

The suppression effects that were found may reveal a dynamic interplay between the difficulties that clients at risk experience in forming an alliance and a compensatory response from therapists that buffers the former effect and protects the therapeutic process, stressing the importance of CT management. According to MacKinnon et al. (2000), a nonsignificant overall relationship between an independent and a dependent variable may lead to the erroneous conclusion that mediation is not present when direct and indirect effects of opposite signs cancel each other and result in a nonzero but nonsignificant overall relationship. This may well be the case with the impact of client clinical variables on the therapeutic process, as illustrated by our preliminary results. Considering that both CORE-OM risk and CFI dimensions had no significant effects on WAI-SR in the absence of each other, our results encourage a careful examination of therapists' statelike, session-specific processes that may that preserve the alliance under the appearance of no effects. CT dynamics of this type may help illuminate the inconsistent findings concerning the effect of therapists' attachment patterns on alliance (see Daniel, 2006). Furthermore, such dynamics may be involved in the findings regarding the interaction between clinical severity and therapists' factors (Bucci et al., 2015; Schauenburg et al., 2010). The way therapists' relational orientations (such as attachment dimensions) concretely affect psychotherapy may be through therapists greater or lesser ability to manage the emotions transpiring within the dyad, or regulate the therapeutic distance, defined by Daly and Mallinckrodt (2009) as the level of transparency and disclosure in the psychotherapy relationship from both client and therapist, together with the immediacy, intimacy, and emotional intensity of a session (p. 559). CT management is certainly a central component of such abilities.
The particular importance of clinical risk for alliance and CT management suggested by our results needs further exploration. Many authors have stressed the necessity to manage CT reactions towards clients' suicidality in order to maintain a productive working alliance (Cureton $\&$ Clemens, 2015). From a wider angle, expressions of anger, interpersonal chaos, and impulsive self-destructive behaviors are common features in borderline personalities, in which cases the strong CT reactions on the therapist side and the lack of an observing ego on the part of the client may represent particular threats to the alliance (Clarkin, Yeomans, \& Kernberg, 2006; Ekeblad, Falkenström, \& Holmqvist, 2016; Hayes et al., 2011). In fact, the challenges that clients' personality disorders represent both to $\mathrm{CT}$ and alliance are in themselves important fields for research (e.g., Colli, Tanzilli, Dimaggio, \& Lingiardi, 2014; Tufekcioglu et al., 2013).

This study has important limitations and caution must be taken concerning its findings. Namely, one must be careful about the small sample size; problematic internal consistency in CFI subscales (possibly due to the self-reported form and/or insufficient sample size) and the CORE risk scale (in line with results from the Portuguese version - Sales et al., 2012); possible distortions due to measurement error (structural equation modelling with latent variables is desirable as soon as sample size allows); and the lack of qualitative data. Hopefully, our ongoing longitudinal study will help overcome some of these problems, while increasing statistical power. Still, significant and theoretically intelligible effects found with a small sample and associating data gathered from different raters at different time-points may signal important tendencies.

We believe future research should explore sessionspecific uses of the CFI and examine the different dimensions of CT management represented by its subscales, despite the need to further investigate its psychometric qualities. More generically, a focus on therapists' psychological work involved in CT management and its role in mitigating challenges coming from clients' characteristics seems promising. Ideally, these processes should be studied along the therapeutic process. Overall, clients' severity of clinical problems and level of personality functioning and the dyad's ability to create a reflective space for effective collaboration are important issues needing further investigation, namely in their impact on the development of a good working alliance.

\section{Conclusions}

In conclusion, our study suggests that clients' clinical difficulties may activate different therapists' $\mathrm{CT}$ management strategies in early stages of psychotherapy. In particular, empathy-based CT management seems to be mobilized in the face of clients' risk of harming themselves and/or others. CT management, and especially em- 
pathic responses, appear to buffer the negative effect of clients' clinical risk on alliance, thus protecting the therapeutic process.

\section{References}

Ackerman, S.J., \& Hilsenroth, M.J. (2001). A review of therapist characteristics and techniques negatively impacting the therapeutic alliance. Psychotherapy: Theory, Research, Practice, Training, 38, 171-185.

Ackerman, S.J., \& Hilsenroth, M.J. (2003). A review of therapist characteristics and techniques positively impacting the therapeutic alliance. Clinical Psychological Review, 23, 1-33.

Barreto, J.F., Carvalho, H.M., \& Matos, P.M. (2014). Inventário de Factores da Contratransferência - Versão Portuguesa [Countertransference Factors Inventory - Portuguese version]. Unpublished manuscript, Center for Psychology at University of Porto, University of Porto, Porto, Portugal.

Bucci, S., Seymour-Hide, A., Harris, A., \& Berry, K. (2015). Client and therapist attachment styles and working alliance. Clinical Psychology and Psychotherapy, doi: 10.1002/cpp.1944

Clarkin, J.F., Yeomans, F.E., \& Kernberg, O.F. (2006). Psychotherapy of borderline personality: Focusing on object relations. Washington, DC: American Psychiatric Publishing.

Colli, A., Tanzilli, A., Dimaggio, G., \& Lingiardi, V. (2014). Patient personality and therapist response: An empirical investigation. American Journal of Psychiatry, 171, 102-108. doi: 10.1176/appi.ajp.2013.13020224

Constantino, M.J., Castonguay, L.G., \& Schut, A.J. (2002). The working alliance: A flagship for the "scientist-practitioner" model in psychotherapy. In G.S. Tryon (Ed.), Counseling based on process research: Applying what we know (pp. 81131). Boston: Allyn \& Bacon.

Cureton, J.L., \& Clemens, E.V. (2015). Affective constellations for countertransference awareness following a client's suicide attempt. Journal of Counseling \& Development, 93, 352-360. doi: 10.1002/jcad.12033

Daly, K.D., \& Mallinckrodt, B. (2009). Experienced therapists' approach to psychotherapy for adults with attachment avoidance or attachment anxiety. Journal of Counseling Psychology, 56, 549-563. doi:10.1037/a0016695

Daniel, S.I.F. (2006). Adult attachment patterns and individual psychotherapy: A review. Clinical Psychology Review, 26, 968-984. doi: 10.1016/j.cpr.2006.02.001

Del Re, A.C., Flückiger, C., Horvath, A.O., Symonds, D., \& Wampold, B.E. (2012). Therapist effects in the therapeutic alliance-outcome relationship: A restricted-maximum likelihood meta-analysis. Clinical Psychology Review, 32, $642-$ 649. doi: 10.1016/j.cpr.2012.07.002

Ekeblad, A., Falkenström, F., \& Holmqvist, R. (2016). Reflective functioning as predictor of working alliance and outcome in the treatment of depression. Journal of Consulting and Clinical Psychology, 84, 67-78. doi: 10.1037/ccp0000055

Evans, C., Connell, J., Barkham, M., Margison, F., McGrath, G., Mellor-Clark, J., \& Audin, K. (2002). Towards a standardised brief outcome measure: Psychometric properties and utility of the CORE-OM. British Journal of Psychiatry, 180, 51-60. doi: 10.1192/bjp.180.1.51

Evans, C., Mellor-Clark, J., Margison, F., Barkham, M., Audin, K., Connell, J., \& McGrath, G. (2000). CORE: Clinical Out- comes in Routine Evaluation. Journal of Mental Health, 9, 247-255. doi: 10.1080/jmh.9.3.247.255

Gelso, C.J., Fassinger, R.E., Gomez, M.J., \& Latts, M.G. (1995). Countertransference reactions to lesbian clients: The role of homophobia, counselor gender, and countertransference management. Journal of Counseling Psychology, 42, 356364. doi: 10.1037/0022-0167.42.3.356

Gelso, C.J., \& Hayes, J.A. (2007). Countertransference and the inner world of the psychotherapist: Perils and possibilities. Mahwah, NJ: Erlbaum.

Gibbons, M.B.C., Crits-Christoph, P., de la Cruz, C., Barber, J., Siqueland, L., \& Gladis, M. (2003). Pretreatment expectations, interpersonal functioning, and symptoms in the prediction of the therapeutic alliance across supportive-expressive psychotherapy and cognitive psychotherapy. Psychotherapy Research, 13, 59-76. doi: 10.1093/ptr/kpg007

Hatcher, R.L., \& Barends, A.W. (1996). Patients' view of the alliance in psychotherapy: Exploratory factor analysis of three alliance measures. Journal of Consulting and Clinical Psychology, 64, 1326-1336.

Hatcher, R.L., \& Gillaspy, J.A. (2006). Development and validation of a revised short version of the Working Alliance Inventory. Psychotherapy Research, 16, 12-25. doi: 10.1080/ 10503300500352500

Hayes, J.A., Gelso, C.J., \& Hummel, A.M. (2011). Managing countertransference. Psychotherapy, 48, 88-97. doi: $10.1037 / \mathrm{a} 0022182$

Horvath, A.O. (1994). Research on the alliance. In A.O. Horvath \& L.S. Greenberg (Eds.), The working alliance: Theory, research, and practice (pp. 259-286). New York: John Wiley $\&$ Sons, Inc.

Horvath, A.O., \& Bedi, R.P. (2002). The alliance. In J.C. Norcross (Ed.), Psychotherapy relationships that work: Therapist contributions and responsiveness to patients (pp. 37-70). New York: Oxford University Press.

Horvath, A.O., Del Re, A.C., Fluckiger, C., \& Symonds, D. (2011). Alliance in individual psychotherapy. Psychotherapy, 48, 9-16. doi: 10.1093/acprof:oso/9780199737208.003.0002

Ligiéro, D.P., \& Gelso, C. (2002). Countertransference, attachment, and the working alliance: The therapist's contribution. Psychotherapy: Theory, Research, Practice, Training, 39, 3-11. doi:10.1037//0033-3204.39.1.3

MacKinnon, D.P., Krull, J.L., \& Lockwood, C.M. (2000). Equivalence of the mediation, confounding, and suppression effect. Prevention Science, 1, 173-181. doi:10.1023/A: 1026595011371

MacKinnon, D.P., Lockwood, C.M., \& Williams, J. (2004). Confidence limits for the indirect effect: Distribution of the product and resampling methods. Multivariate Behavioral Research, 39, 99-128. doi: 10.1207/s15327906mbr3901_4

Nissen-Lie, H.A., Monsen, J.T., \& Rønnestad, M.H. (2010). Therapist predictors of early patient-rated working alliance: A multilevel approach. Psychotherapy Research, 20, 627 646. doi: 10.1080/10503307.2010.497633

Norcross, J.C., \& Wampold. B.E. (2011). Evidence-based therapy relationships: Research conclusions and clinical practices. Psychotherapy, 48, 98-102. doi: 10.1037/a0022161

Ramos, M.A.F. (2008). Análise das características psicométricas da versão portuguesa do Working Alliance Inventory Short Revised [Analysis of the psychometric qualities of the Working Alliance Inventory - Short Revised] (Master's thesis). Available from: http://repositorium.sdum. uminho.pt/ 
Rosenberger, E.W., \& Hayes, J.A. (2002). Origins, consequences, and management of countertransference: A case study. Journal of Counseling Psychology, 49, 221-232. doi: 10.1037//0022-0167.49.2.221

Rubino, G., Barker, C., Roth, T., \& Fearon, P. (2000). Therapist empathy and depth of interpretation in response to potential alliance ruptures: The role of therapist and patient attachment styles. Psychotherapy Research, 10, 408-420. doi: $10.1093 / \mathrm{ptr} / 10.4 .408$

Sales, C.M.D., Moleiro, C., Evans, C., \& Alves, P. (2012). Versão Portuguesa do CORE-OM: Tradução, adaptação e estudo preliminar das suas propriedades psicométricas [Portuguese version of the CORE-OM: Translation, adaptation, and preliminary study of its psychometric properties]. Revista de Psiquiatria Clínica, 39, 54-59. doi: 10.1590/s0101-60832012000200003

Sauer, E.M., Lopez, F.G., \& Gormley, B. (2003). Respective contributions of therapist and client adult attachment orien- tations to the development of the early working alliance: A preliminary growth modeling study. Psychotherapy Research, 13, 371-382. doi:10.1093/ptr/kpg027

Schauenburg, H., Bucheim, A., Beckh, K., Nolte, T., Brenk, K., Leichesenring, F., Strack, M., \& Dinger, U. (2010). The influence of psychodynamically oriented therapists' attachment representations on outcome and alliance in inpatient psychotherapy. Psychotherapy Research, 20, 193-202. doi: 10.1080/10503300903204043

Tufekcioglu, S., Muran, J.C., Safran, J.D., \& Winston, A. (2013). Personality disorder and early psychotherapy process in two time-limited therapies. Psychotherapy Research, 23, 646657. doi: 10.1080/10503307.2013.843803

Zilcha-Mano, S., Solomonov, N., Chui, H., McCarthy, K.S., Barrett, M.S., \& Barber, J.P. (2015). Therapist-reported alliance: Is it really a predictor of outcome? Journal of Counseling Psychology, 62, 568-578. doi: 10.1037/cou0000106 